\title{
Sq (H) Solar Variation at Yaoundé-Cameroon AMBER Station from 2011 to 2014
}

\author{
Messanga Etoundi Honoré ${ }^{*}$, Fatma Anad ${ }^{2}$, Ngabireng Claude Marie ${ }^{3}$, Mbane Biouele César ${ }^{1}$ \\ ${ }^{1}$ Laboratory of Earth's Atmosphere Physics, Department of Physics, University of Yaoundé 1, Yaoundé, Cameroon \\ ${ }^{2}$ Centre de Recherche en Astronomie, Astrophysique et géophysique, Algiers, Algéria \\ ${ }^{3}$ Laboratory of non-linear Physics-ENSP, University of Yaoundé 1, Yaoundé, Cameroon \\ Email: *honormess@yahoo.fr
}

How to cite this paper: Honoré, M.E., Anad, F., Marie, N.C. and César, M.B. (2017) Sq $(\mathrm{H})$ Solar Variation at Yaoundé-Cameroon AMBER Station from 2011 to 2014. International Journal of Geosciences, 8, 545562.

https://doi.org/10.4236/ijg.2017.84029

Received: October 28, 2016

Accepted: April 25, 2017

Published: April 28, 2017

Copyright (C) 2017 by authors and Scientific Research Publishing Inc. This work is licensed under the Creative Commons Attribution International License (CC BY 4.0).

http://creativecommons.org/licenses/by/4.0/

\begin{abstract}
This paper presents the earth's magnetic field variations on quiet days using data from 2011 to 2014 provided by the AMBER station located at the University of Yaoundé 1 (Cameroon), whose geographic and geomagnetic coordinates are respectively: $\left(3.87^{\circ} \mathrm{N}, 11.52^{\circ} \mathrm{E}\right)$ and $\left(5.8^{\circ} \mathrm{S}, 83.1^{\circ} \mathrm{E}\right)$. The variability of the $\mathrm{H}$ horizontal component of the Earth's magnetic field was examined using the North (X) and East ( $\mathrm{Y}$ ) components of the earth's magnetic field. The $\mathrm{H}$ component is then used to calculate and analyze the diurnal, monthly and seasonal Solar quiet variations Sq $(\mathrm{H})$ observed in Yaoundé-Cameroon during quiet magnetic days. The results obtained show that the $\mathrm{Sq}(\mathrm{H})$ variations are seasonal. e.g., in Spring the Sq $(\mathrm{H})$ amplitude $(\sim 72 \mathrm{nT})$ is larger than that of Autumn ( 69 nT). The maximum values of Sq $(\mathrm{H})$ vary from $48.8 \mathrm{nT}$ to 57.12 $\mathrm{nT}$ in summer and from $41 \mathrm{nT}$ to $60 \mathrm{nT}$ in winter from the years 2011 to 2014 . In general, these maximum values are observed around 12:00 and 13:00 in local time. These results show that the morphology of $\mathrm{Sq}(\mathrm{H})$ in Yaoundé is presented as a function of seasons. Moreover, the $\mathrm{Sq}(\mathrm{H})$ values are negative during morning hours (01:00 - 06:00) and afternoon hours (18:00 - 24:00) in local time throughout all months and all seasons. This significant negative excursion of $\mathrm{Sq}(\mathrm{H})$ in Yaoundé during the night time might be due to other physical processes such as storms or thunderclouds or to the existence of a strong induced current in Yaoundé which can affect the ground-based instruments. By referring to the solar cycle 24, our results show that the $\mathrm{Sq}(\mathrm{H})$ amplitude varies with the solar activity. The aim of this work is to analyze the diurnal, monthly and seasonal variations of $\mathrm{Sq}(\mathrm{H})$ observed in Yaoundé from 2011 to 2014.
\end{abstract}

\section{Keywords}

Sq (H) Amplitude, Sq (H) Diurnal, Monthly and Seasonal Variations, Solar Cycle 24 


\section{Introduction}

The existence of the regular diurnal variation of the earth's magnetic field had been discovered in 1722 by Graham. In 1882, [1] was the first to propose that, atmospheric motions are the sources of ionospheric electric currents which cause the regular variations of the geomagnetic field. Reference [2] defined what was the Mean Diurnal Regular Variation of the earth's magnetic field denoted Sq as observed during the quiet magnetic days. The classification of days according to their magnetic activity level was introduced first in 1905, using the Ci index to select the five quietest days per month. Reference [3] proposed the method (still used) based on the use of the three-hour Kp indices, to select the five quietest days as well as the five most disturbed days. But, [4] in his work on the classification of the international magnetic days, reached the following conclusion: the classification of magnetic disturbed days is not significant due to the diversity of magnetic disturbances. He proposed to stop this classification.

The earth's magnetic field data were used and are still used for the study of ionospheric and magnetospheric electric currents, both for atmospheric and oceanic tides and for seismicity. The AMBER (African Meridian B-field Education and Research) magnetometer is one of the ground-based instruments which provide the earth's magnetic field data. This magnetometer network had been deployed in Africa under the IHY (International Heliophysical Year) program [5]. The AMBER array currently has fifteen magnetometers across Africa, Asia and America (11 are already deployed and the others are in the process of deployment). The main objective of the AMBER project is to study the electrodynamic processes that govern the equatorial ionosphere in the African sector and compare and contrast them with electrodynamics in other longitude sectors.

It has long been established that variations in magnetic field recorded by ground-based instruments are caused by dynamo action in the upper atmosphere [6]. These daily variations of the earth's magnetic field during quiet conditions are known to be associated with the dynamos currents that are driven by thermal and wind tidal motions in the E-region of the ionosphere [7]. The equatorial electrojet is a phenomenon that has attracted the attention of several researchers both in the past and recent times. Reference [8], in his work reminds us that the Sq current is the cause of the generation of an east-west electrostatic field at the equatorial ionosphere, which is directed eastward during daytime. At the magnetic dip equator, where the earth's magnetic field is horizontal, this electric field results from an intense current flowing eastward along the magnetic equator known as the Equatorial Electrojet (EEJ). The Equatorial Electrojet (EEJ) is a system of current flowing from the west to the east in the E-region of the earth's ionosphere during daytime in a relatively narrow band $(600 \mathrm{~km}$ and within $\pm 3^{\circ}$ ) centered on the magnetic equator. Since its discovery, the equatorial electrojet has been the subject of several studies. Most of the first studies were carried out to explain the generating mechanisms such as an intense current flowing along the magnetic equator. Since the $1970 \mathrm{~s}$, few physical theories and models of the ionospheric dynamo have been developed in order to explain the 
mechanism of the equatorial electrojet flow and its main features such as diurnal and seasonal variability, counter-electrojet, etc.

The diurnal and seasonal variations of the solar quiet (Sq) variations had been analyzed recently by several researchers [9] [10]. In this paper, we continue this analysis using the data provided by the Yaoundé station during quiet magnetic days from 2011 to 2014 in order to characterize it.

\section{Data set and Method of Analysis}

The installation of ground-based instruments has been improved considerably after the launch of the United Nations-sponsored International Space Weather Initiative (ISWI) program, which is an extension of the International Heliophysical Year (IHY), which has facilitated the deployment of a number of small instruments arrays, including magnetometers [8] [11]. The installation of these instruments made it possible to cover the largest landmass that existed along the geomagnetic equator, especially in regions that had been devoid of ground-based instruments such as in Africa.

The magnetic data used in this study are those provided by one of the AMBER stations installed in Yaoundé-Cameroon since 2009, whose geographical and geomagnetic coordinates are respectively: $\left(3.87^{\circ} \mathrm{N}, 11.52^{\circ} \mathrm{E}\right)$ and $\left(5.8^{\circ} \mathrm{S}, 83.1^{\circ} \mathrm{E}\right)$. It provides continuous recordings of the earth's magnetic field. Its geographical position in relation to the global network of AMBER magnetometers is given in Figure 1. The methods of the data processing and analysis used in this study are those already used by several researchers in their recent work [12] [13] [14] [15] [16].

In this analysis, the data set used, consists of the minute values of the earth's magnetic components north $(\mathrm{X})$ and east $(\mathrm{Y})$. Thus, these data are averaged to hourly values. The data are sampled at $2 \mathrm{~Hz}$ (time resolution: $0.5 \mathrm{sec}$ ), and are labeled with an accuracy of $10^{-6} \mathrm{~s}$ [5]. Our station provides the geomagnetic data in the XYZ coordinate system as defined by [17]. By a simple geometry, the $H$ horizontal component is obtained by converting $X$ and $Y$ components according to Equation (1). The concept of local time (LT) was used in this analysis, so

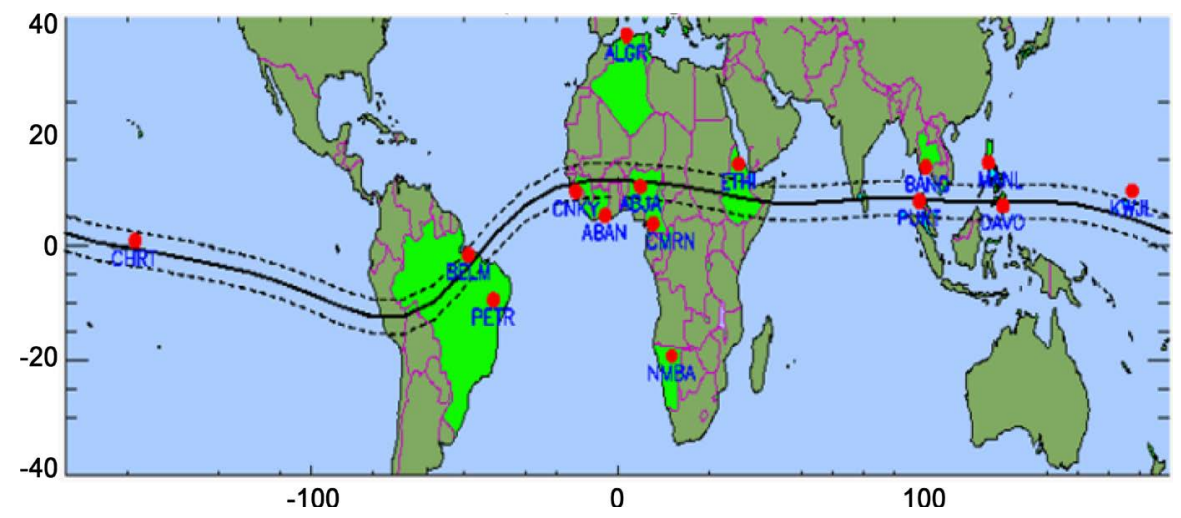

Figure 1. Geographic location of the Global AMBER Equatorial magnetometers Network, one of them (CMRN) has been used for this study. The solid horizontal line depicts the geomagnetic equator, and the two dashed lines indicate the EEJ region. 
Yaoundé station is located at one hour ahead Greenwich Mean Time (GMT + 1). The five international quiet days have been selected and are those universally recognized by the World Data Center (WDC).

$$
H=\sqrt{X^{2}+Y^{2}}
$$

The night time value or baseline value is the average of the $H$ component night time (23:00 - 02:00 LT) value of the earth's magnetic field. The baseline value is given by Equation (2):

$$
H_{0}=\frac{H_{23}+H_{24}+H_{01}+H_{02}}{4}
$$

Where $H_{23}, H_{24}, H_{01}$ and $H_{02}$ are respectively the hourly values of $H$ at 23:00, 24:00, 01:00 and 02:00 in local time (LT). This baseline value is subtracted from the measurement data to obtain the hourly departure of $H$ denoted $\Delta H$. The hourly departure is expressed by Equation (3):

$$
\Delta H(t)=H(t)-H_{0}
$$

Where $t$ is the time in hours ranging from 01:00 to 24:00 LT.

The hourly departure $\Delta H$ is then corrected by the non-cyclic variation. This correction was proposed by some authors [18] [19] and defined non-cyclic variation as a phenomenon in which the value at 01:00 TL is different from that of local midnight (24:00 TL). This correction of the non-cyclic variation is obtained by making a linear adjustment on the daily hourly values such that the values of $\Delta H$ at $01: 00,02: 00, \ldots, 24: 00$ are considered as $\Delta H_{01}, \Delta H_{02}, \cdots, \Delta H_{24}$.

$$
\Delta c=\frac{\Delta H_{01}-\Delta H_{24}}{23}
$$

The linearly adjusted values are expressed as follows in Equation (5):

$$
\sum_{i=1}^{24} \Delta H_{i}+(i-1) * \Delta c
$$

In other words, the hourly departure $\Delta H$ corrected by the non-cyclic variation gives the $S q$ values as shown in Equation (6):

$$
S q_{t}=\Delta H_{t}+(t-1) * \Delta c
$$

After having selected the international quiet days, this last equation is used to obtain the solar daily variation in $\mathrm{H}$ denoted $\mathrm{Sq}(\mathrm{H})$. Thus, the diurnal variation was obtained by calculating the average of Sq $(\mathrm{H})$ hourly values across the five international quiet days of each individual month. The seasonal variations are also obtained by averaging $\mathrm{Sq}(\mathrm{H})$ values of the months for each season. These seasonal variations are calculated following Lloyd's seasons [20]. The months of the year are classified into three seasons: December or D-Season (January, February, November, and December), Equinox or E-season (March, April, September, and October), June Solstice or J-Season (May, June, July, and August).But we have separated the E-season in two equinoxes as [9] and [10] had separated in their study. So we have spring equinox (March, April) and Autumnal equinox (September, October).

Figure 2 illustrates the ideal Sq current system [21] which is composed of two 


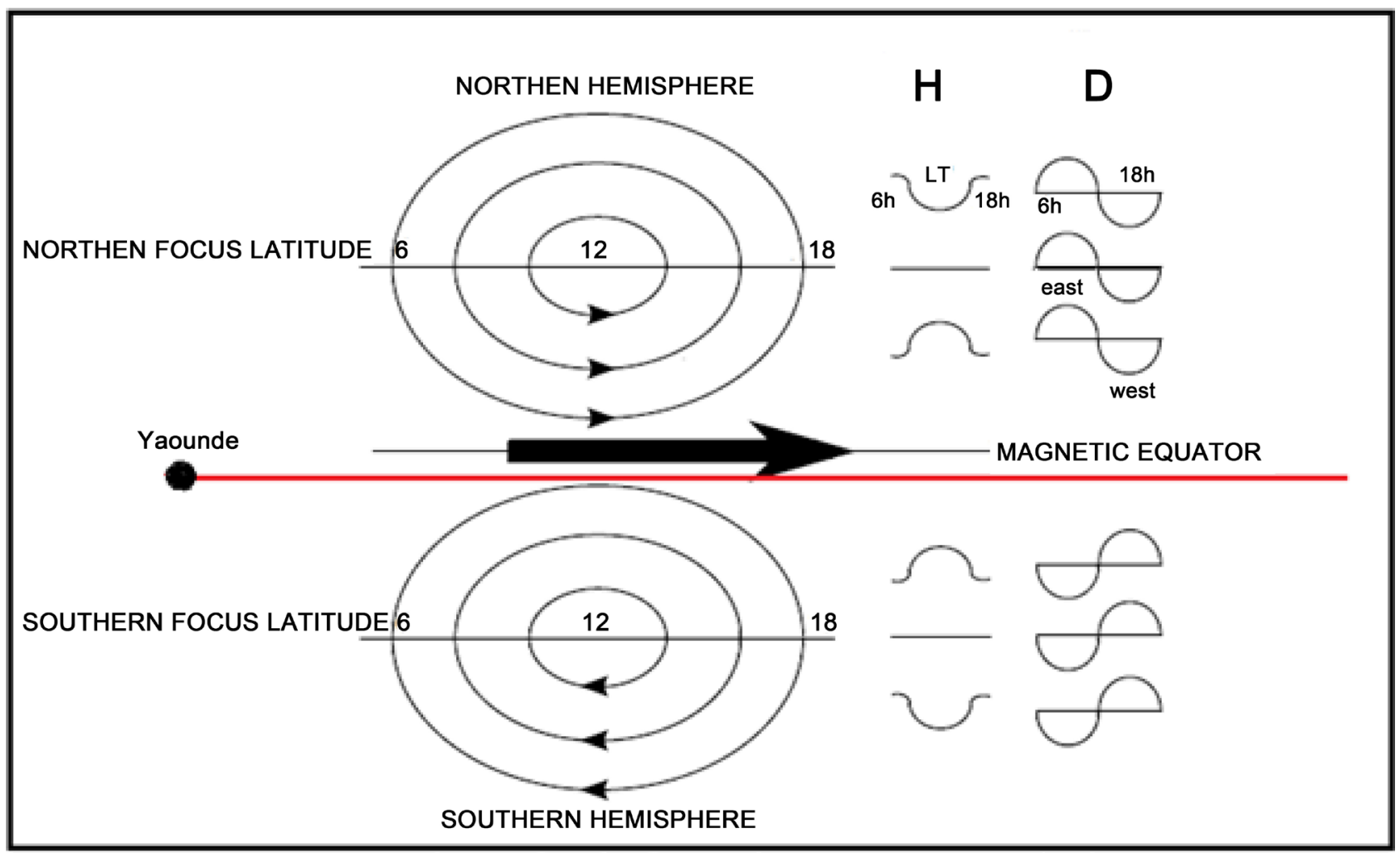

Figure 2. Sq equivalent current system composed of two current cells.

vortices centered on the local noon, one in each hemisphere. In the Northern Hemisphere, the current flows counterclockwise and clockwise in the southern hemisphere. On the right side of this figure are drawn the variations of the $\mathrm{H}$ and D components of the earth's magnetic field seen by an observer during the day and at various places (at the focus, above and below each cell in each hemisphere ) [4]. The Yaoundé station is located above the focus of the Southern vortex closest to the equatorial electrojet. In Yaoundé, $\mathrm{Sq}(\mathrm{H})$ is positive and is eastward ionospheric current (named model type E, pure maximum by [22]).

\section{Results and Discussion}

\subsection{Monthly Diurnal Variations}

Figures 3(a)-(1) show the monthly mean diurnal variation of Sq (H) observed in Yaoundé from January to December for the years 2011 to 2014. The colored curves correspond to different years of the period of study during the solar cycle 24. The maximum of Sq (H) amplitude is respectively $79.07 \mathrm{nT}, 69.72 \mathrm{nT}, 69.64$ $\mathrm{nT}$ and $76 \mathrm{nT}$ for the years 2011, 2012, 2013 and 2014.There is also a lack of curves for 2013 during the months of February to June, this is due to data gaps during this period. The $\mathrm{Sq}(\mathrm{H})$ variations are generally low during the night-time and oscillate between $-10 \mathrm{nT}$ and $0 \mathrm{nT}$. During the daytime, the $\mathrm{Sq}(\mathrm{H})$ variations exhibit this morphology of Sq:

- $\mathrm{Sq}(\mathrm{H})$ is mainly positive for all months and its maximum is generally observed around local noon and 13:00 local time, except in February 2011 where its 
M. E. Honoré et al.
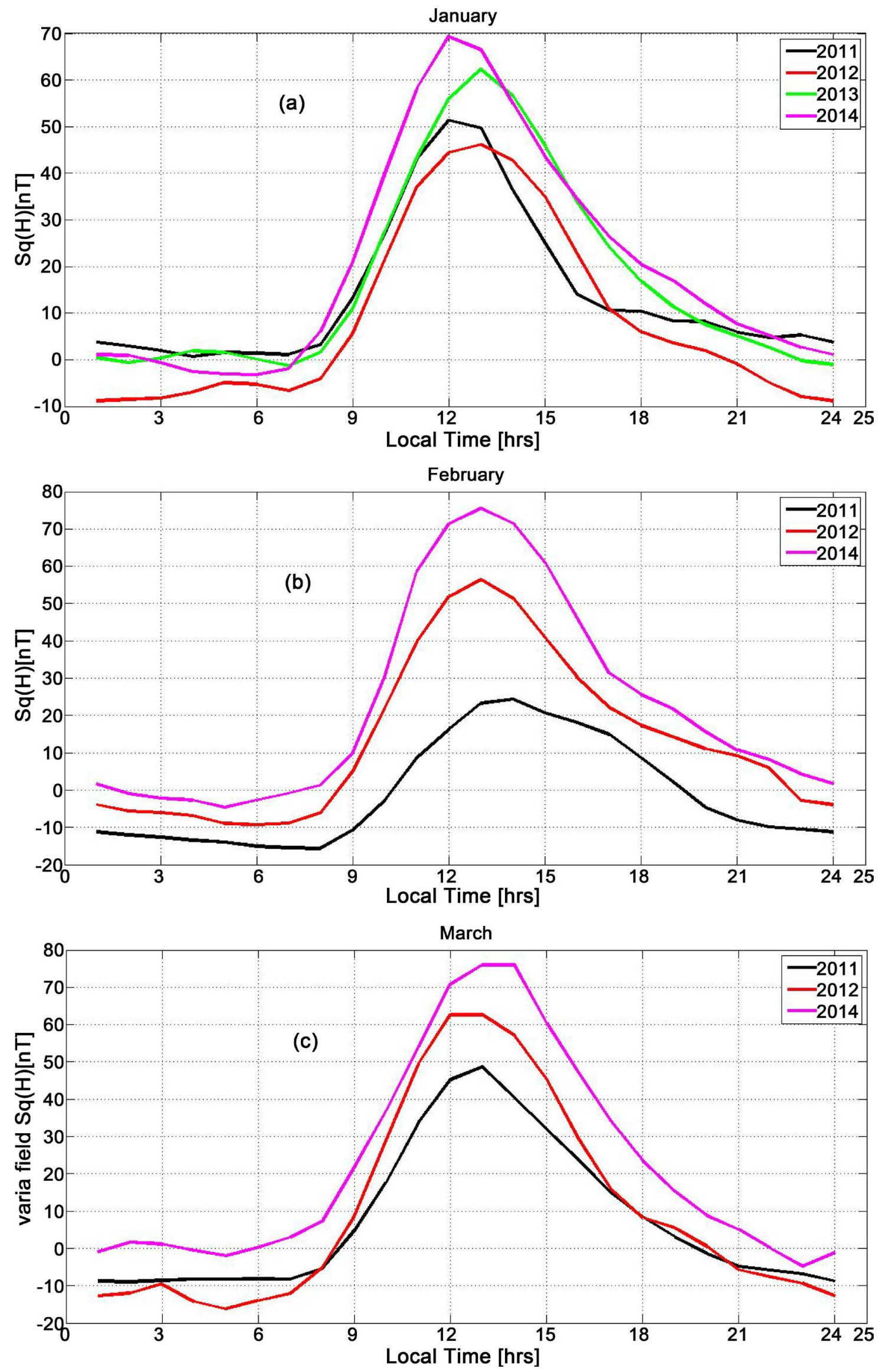

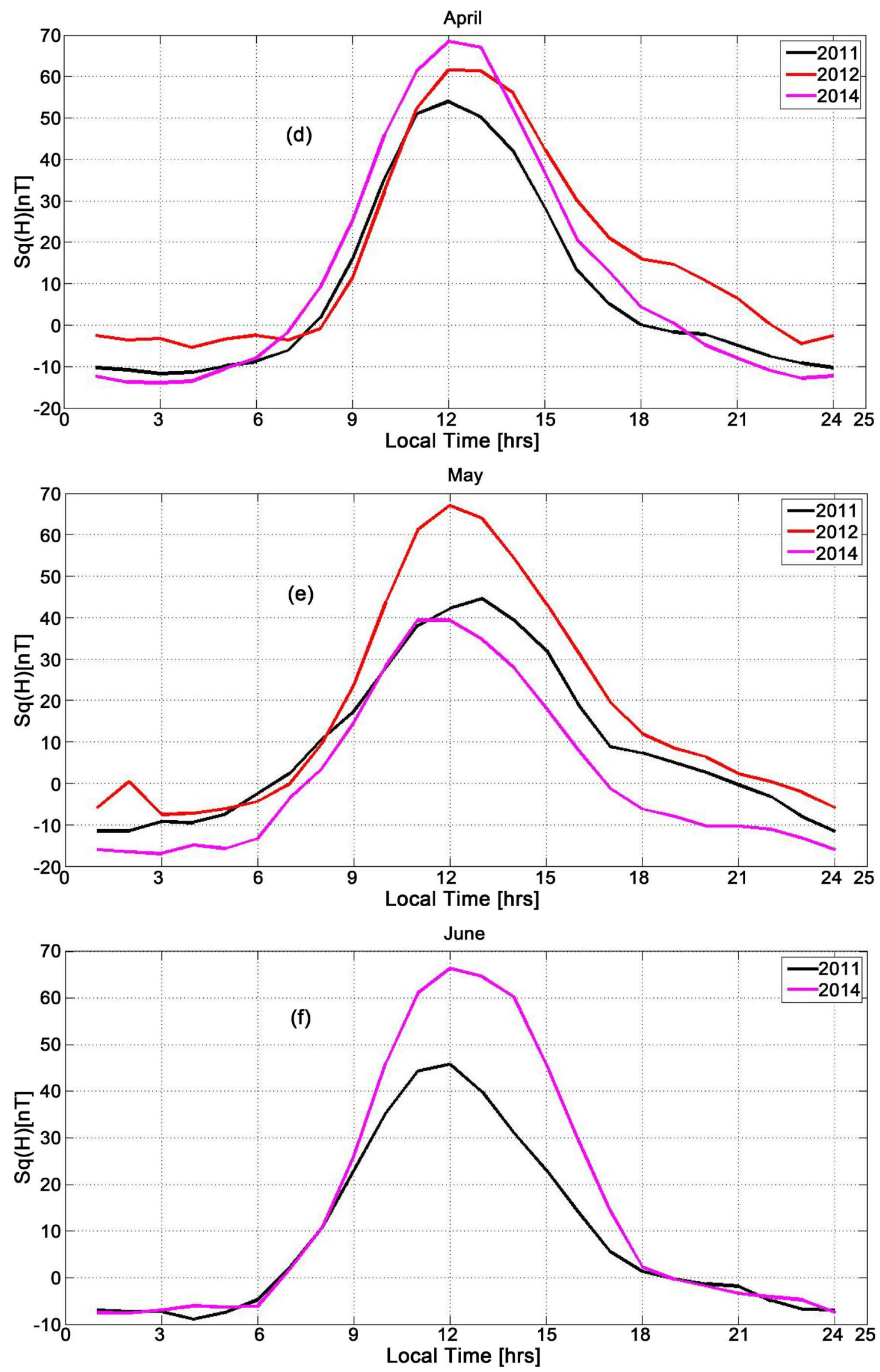
M. E. Honoré et al.
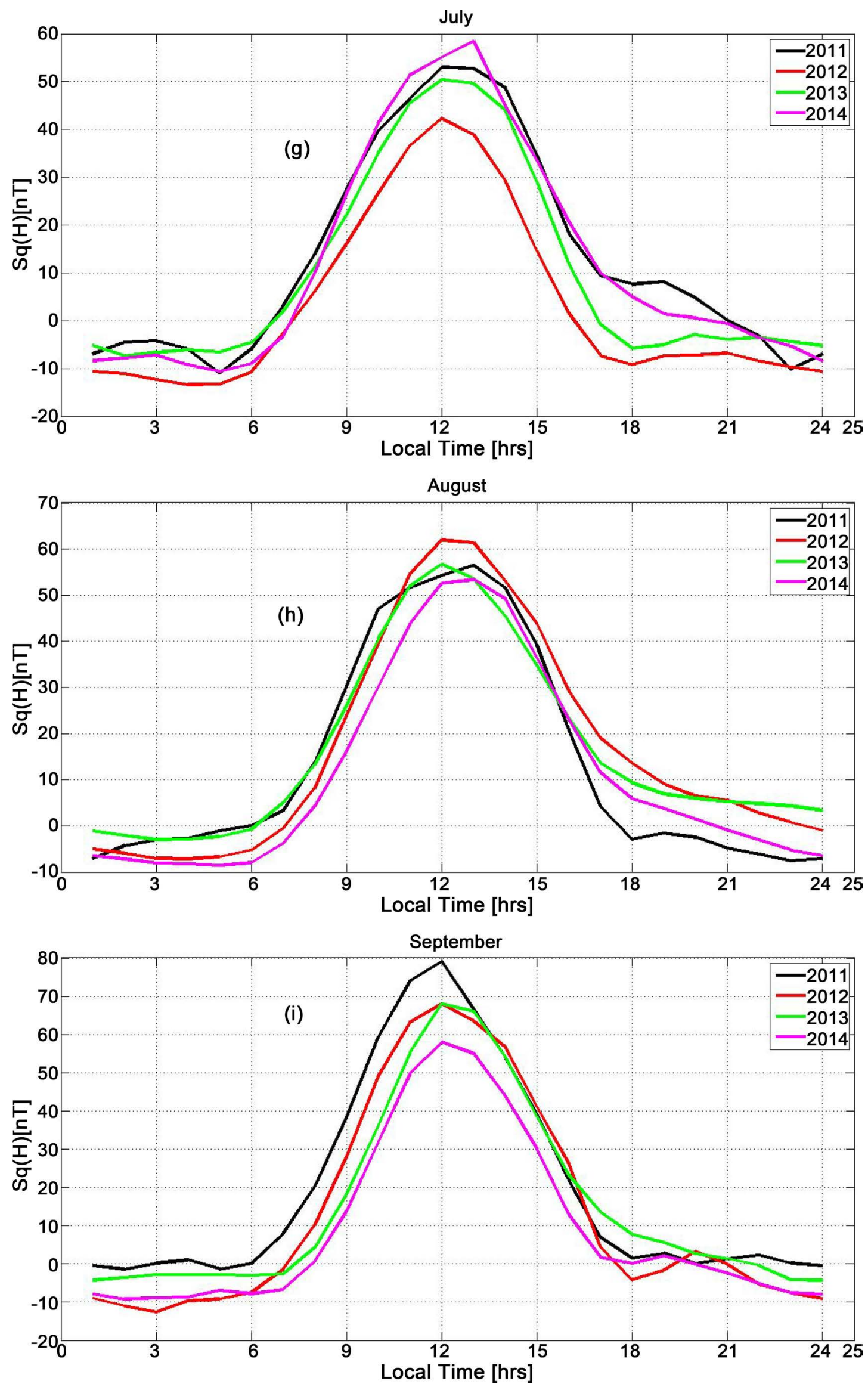

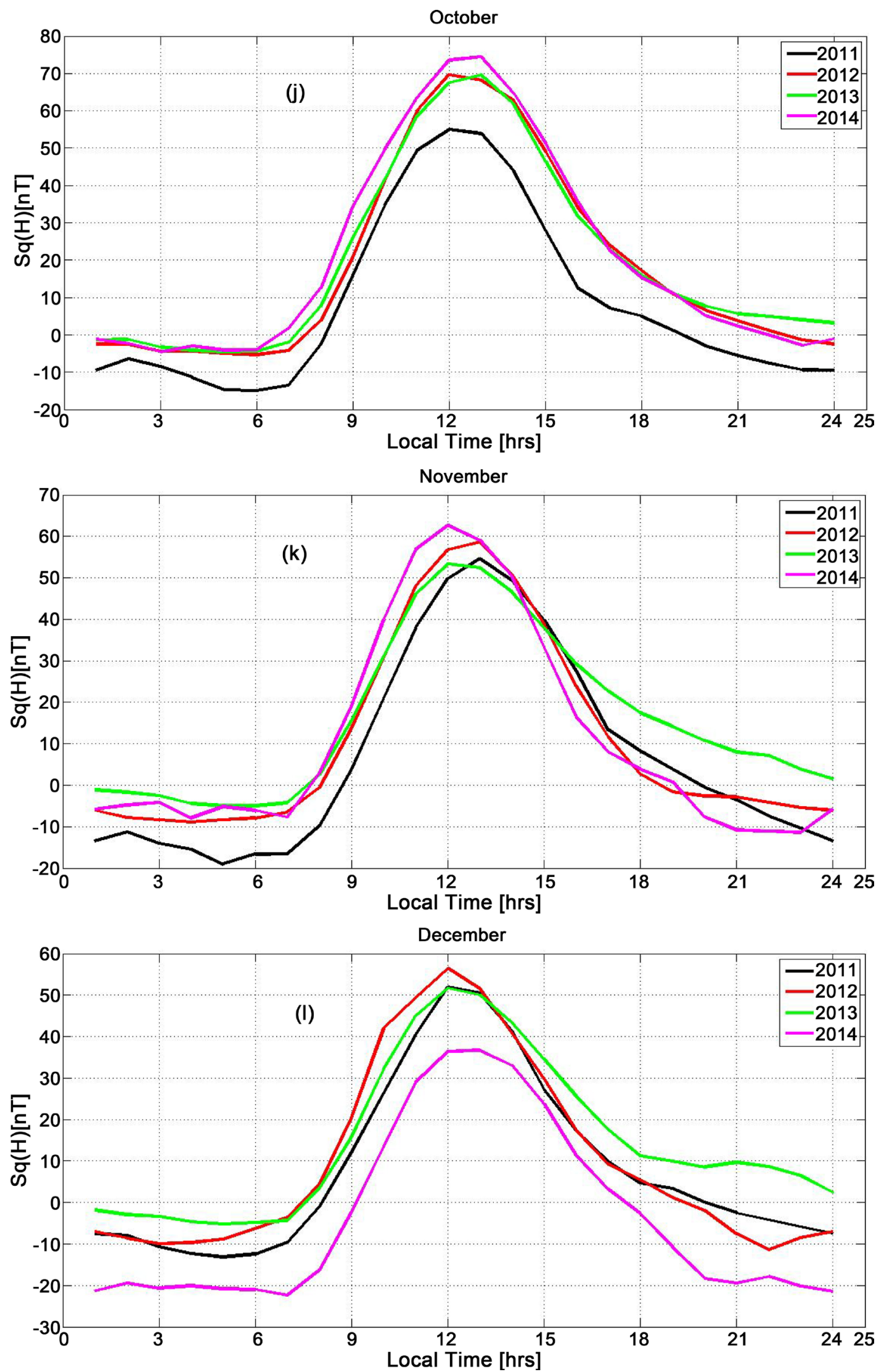

Figure 3. Monthly mean diurnal variations of Sq $(\mathrm{H})$ of earth's magnetic field observed at Yaoundé-Cameroon during quiet magnetic days from January 2011 to December 2014. 
maximum reached at 14:00 LT. This observation is in agreement with [23] and [24] in their work on the diurnal variation model of Sq, they showed that, the maximum intensity of the Sq arrives around 12:00 (local time). This is a typical signature of a station located between the focus of the Sq cell and the equatorial electrojet in the Southern Hemisphere as shown in Figure 2, as is the case for the Yaoundé station.

- The Sq $(\mathrm{H})$ amplitude is in general large, this is due to the fact that at low latitudes, the $\mathrm{Sq}(\mathrm{H})$ component is amplified due to the superposition of the Sq and the EEJ. This is in agreement with [25] who showed that the Sq $(\mathrm{H})$ is expected to exhibit a consistent maximum within electrojet zone as a result of the EEJ phenomenon. References [26] [27] [28] show that enhanced cowling conductivity along the magnetic equator is a major cause of EEJ. Figure 4 shows the $\mathrm{Sq}(\mathrm{H})$ maximum for each month of the year versus the time of passage of this maximum. The maximum amplitude of $\mathrm{Sq}(\mathrm{H})$ varies from 24.35 to $79.07 \mathrm{nT}$, 42.33 to $69.72 \mathrm{nT}, 50.40$ to $69.64 \mathrm{nT}$ and from 36.66 to $76 \mathrm{nT}$ in $2011,2012,2013$ and 2014 , respectively.

Figure 5 shows the progression of the solar cycle and shows that the $24^{\text {th }}$ cycle had two peaks of activity. The first peak at the end of 2011 until early 2012 and the second in early 2014. In addition, the sunspot number is about 103 in February 2014 and remains between 60 and 105 throughout the year 2014. That explains why the Sq intensity values $(\mathrm{H})$ are great during the years 2012 and 2014 observed in Figures 3(a)-(1). At the end of 2011, the sunspot number is between 60 and 97. During this period the Sq $(\mathrm{H})$ amplitude is greater than $60 \mathrm{nT}$. Although the data used in this study are insufficient, it is noted that the Sq $(\mathrm{H})$ variation depends on the solar activity. These results show the strong correlation

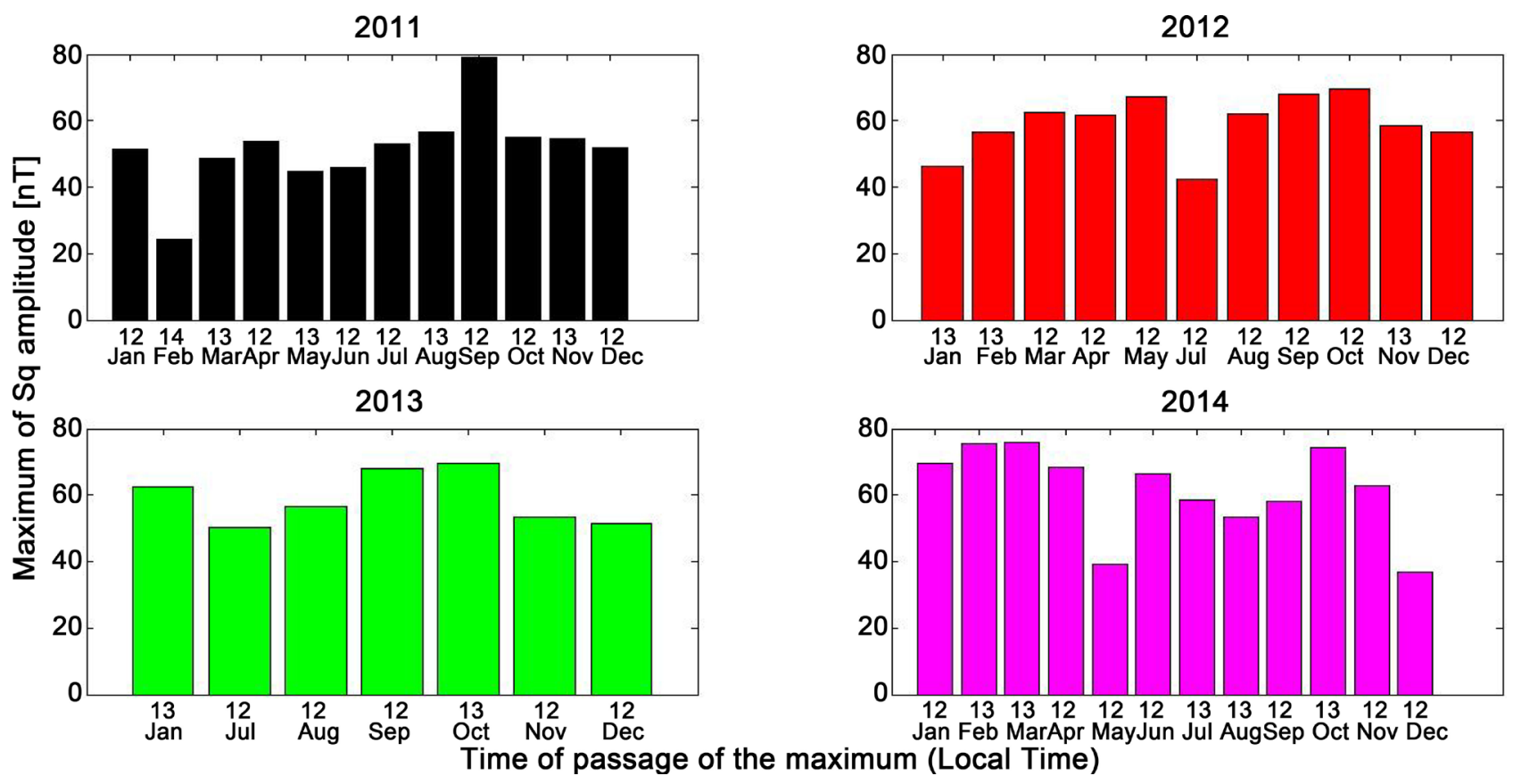

Figure 4. Diagram of maximum of Sq amplitude. Each plot shows the maximum of Sq amplitude versus time of passage of the maximum in local time for individual year. 


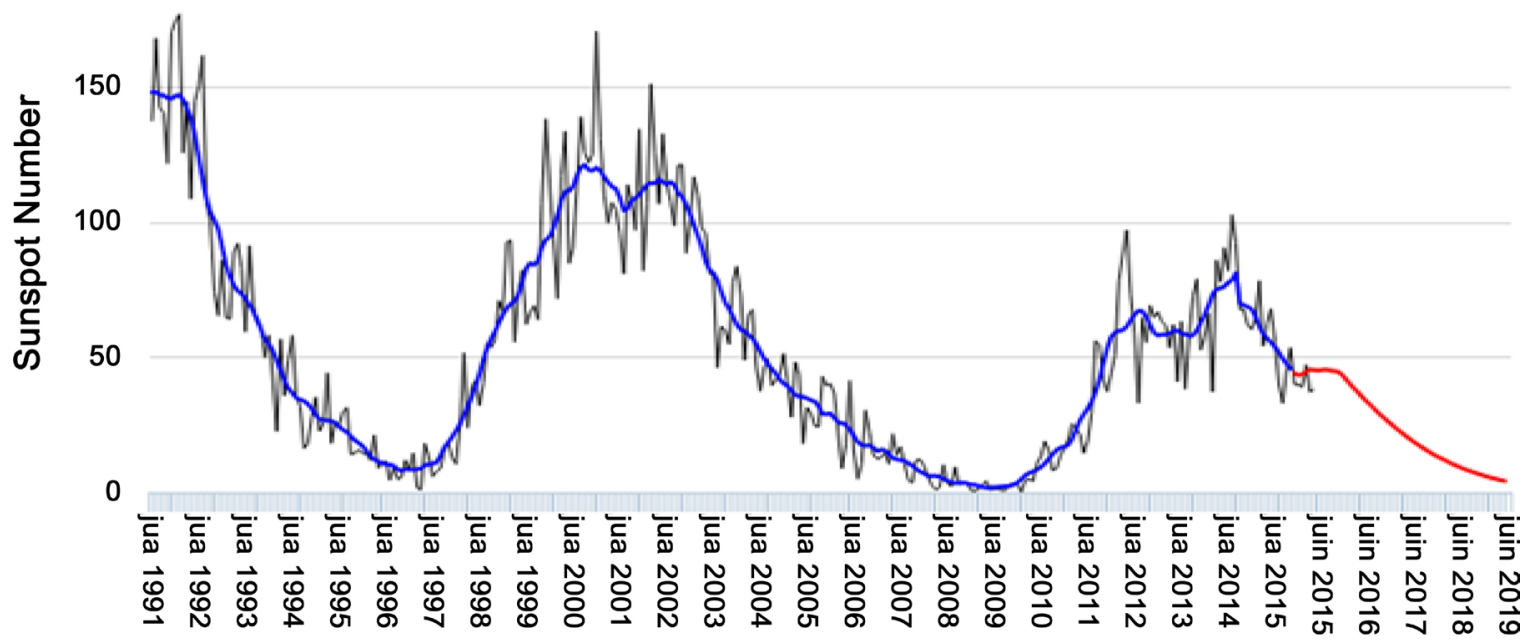

- Observed Sunspot Number *-Smoothed Sunspot Number $*$ Predicted Sunspot Number

Figure 5. Sunspot number and solar cycle progression (Source: Space Weather Prediction Center (SWPC)).

that could exist between the Sq amplitude and the solar cycle variation as [9] had demonstrated in his works.

\subsection{Seasonal Variations}

Figures 6(a)-(d) present the seasonal mean variation of Sq $(\mathrm{H})$ observed in Yaoundé for the years 2011 to 2014 during the four seasons: spring (Figure 6(a)), the autumn (Figure 6(b)), summer (Figure 6(c)) and winter (Figure 6(d)). The colored curves correspond to the different years from 2011 to 2014 for each season. The Sq $(\mathrm{H})$ amplitude in spring $(\sim 72 \mathrm{nT})$ is different from that of the autumn $(\sim 69 \mathrm{nT})$ while that of summer $(\sim 57 \mathrm{nT})$ and the winter $(\sim 60 \mathrm{nT})$. Figures 7(a)-(d) shows that the $\mathrm{Sq}(\mathrm{H})$ amplitude in the autumn is greater than that of the spring during the years 2011, 2012 and 2013. These results show that, there is an equinoctial asymmetry at Yaoundé station. However, we observe that the $\mathrm{Sq}(\mathrm{H})$ variation exhibits a significant negative excursion during the nighttime. This signature is typical of our station, because at this location, the Sq current during the night side is expected to converge to zero. Except in the situation of the existence of a counter-electrojet where a depression or inversion of the magnetic field variation is observed during the morning and the afternoon hours. This result leads us to the assumption of the existence of a strong induced current in Yaoundé or another type of current (external current during night time which could be westward or eastward currents) detected by our magnetometer at our station Which could considerably influence the variation of the horizontal component of the magnetic field in Yaoundé. These negative values of the Sq $(\mathrm{H})$ in our station could also be explained by the existence of a type of electrojet, recently discovered by [29] called tropospheric equatorial. It is a phenomenon of electrification of the troposphere whose source could be some weather events such as thunderstorms and flashes of lightning that accompany 
M. E. Honoré et al.
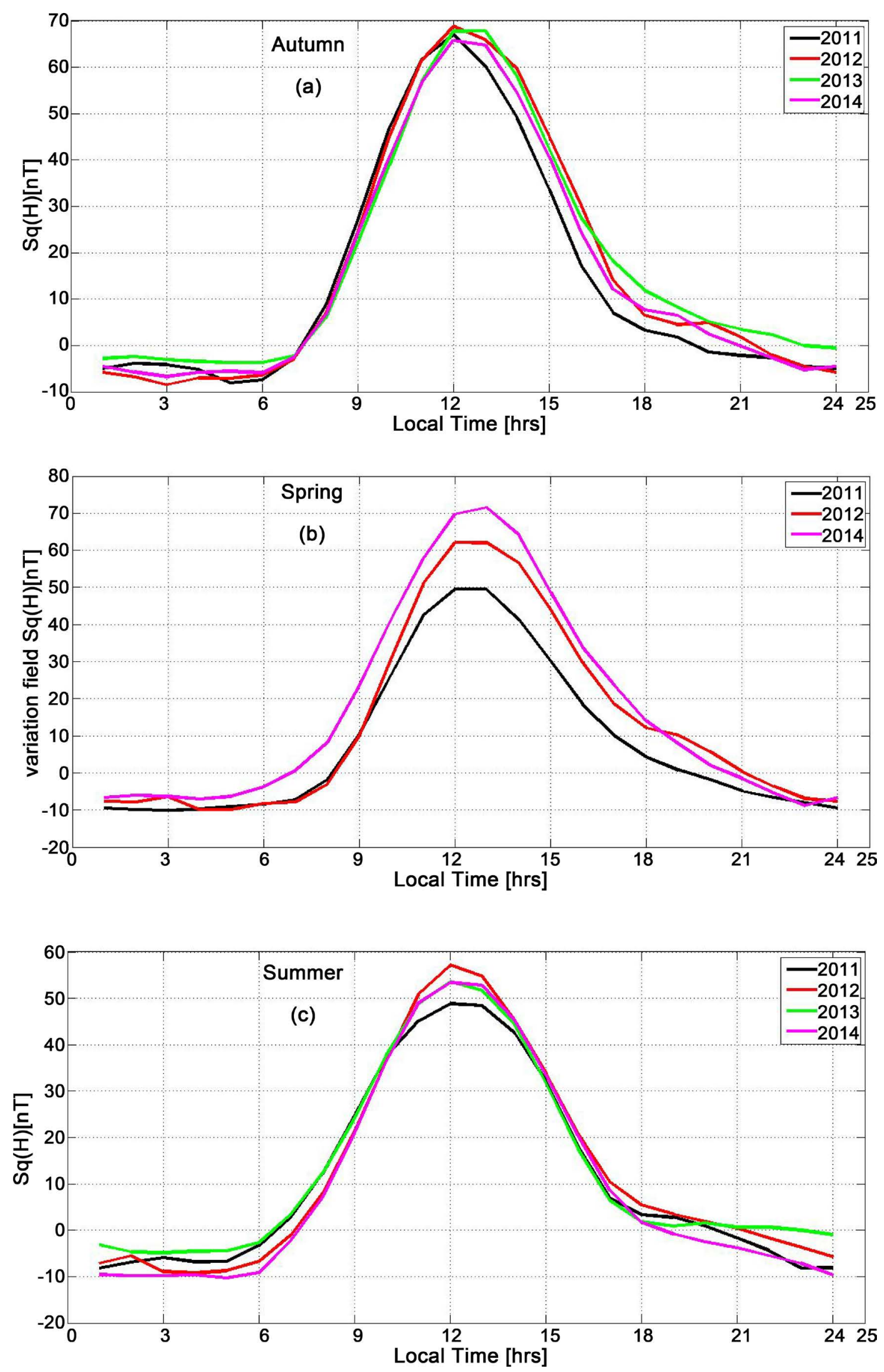


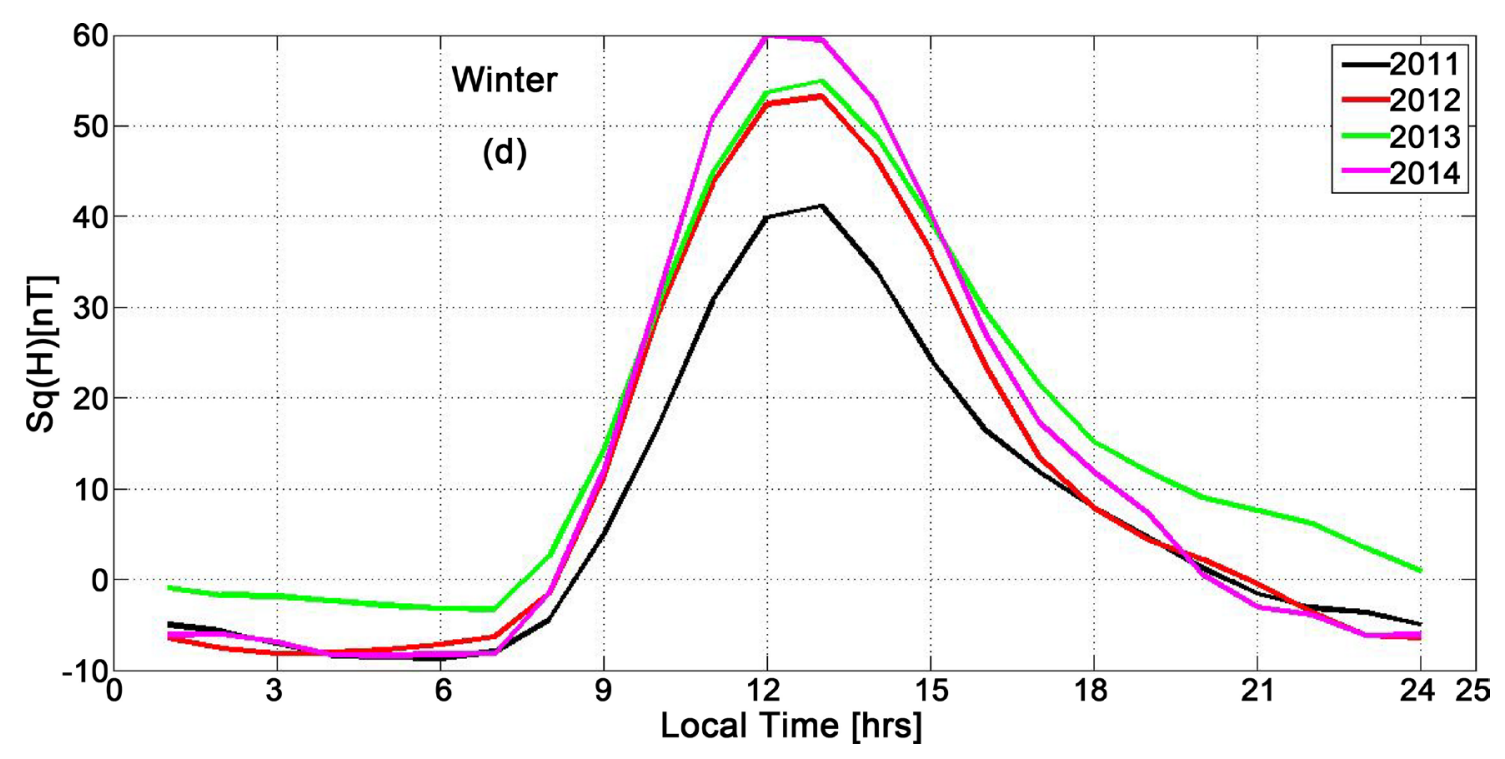

Figure 6. Seasonal mean diurnal variations of Sq (H) of earth's magnetic field observed at Yaoundé-Cameroon during quiet magnetic days for all the years from 2011 to 2014 .
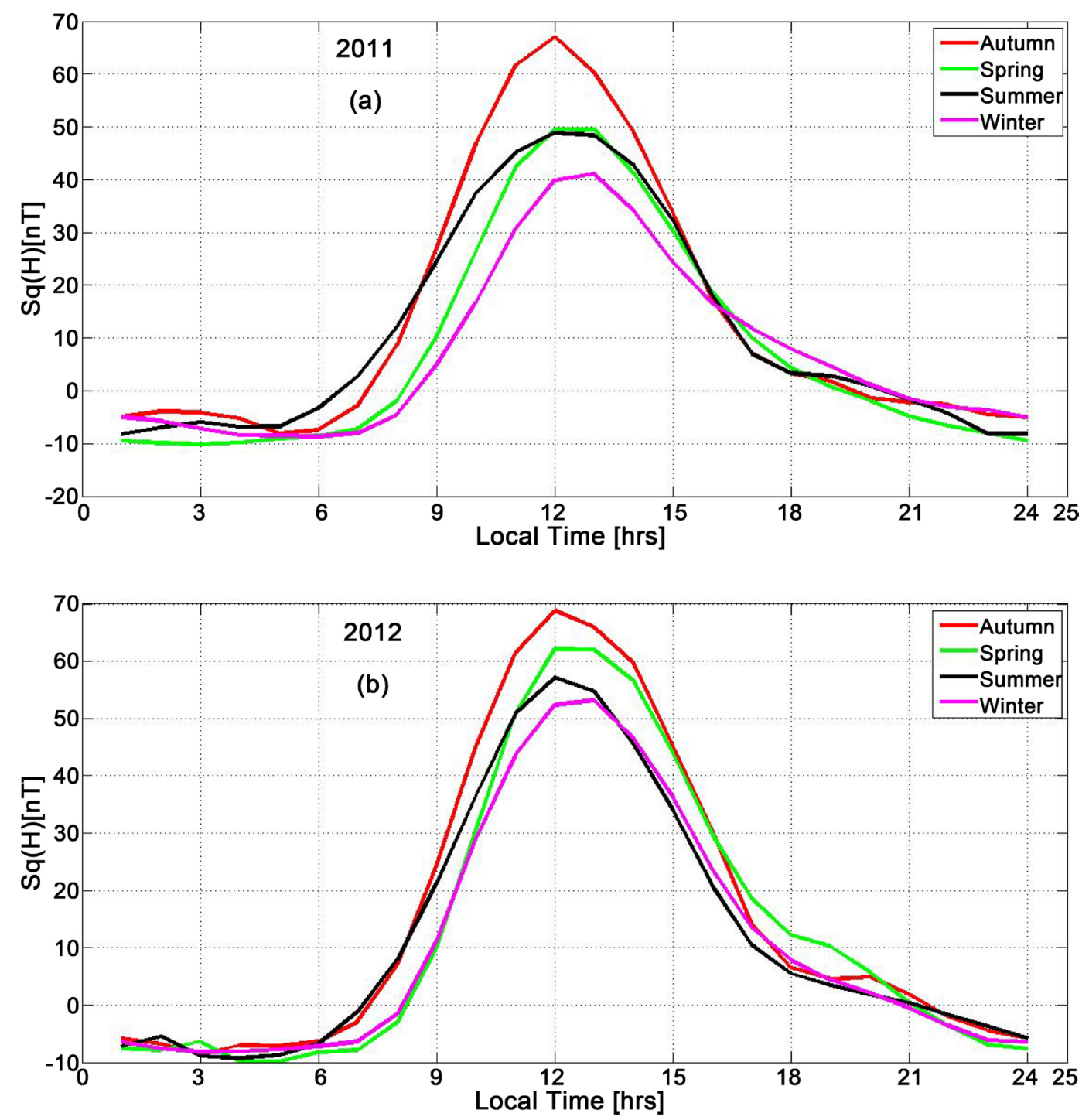

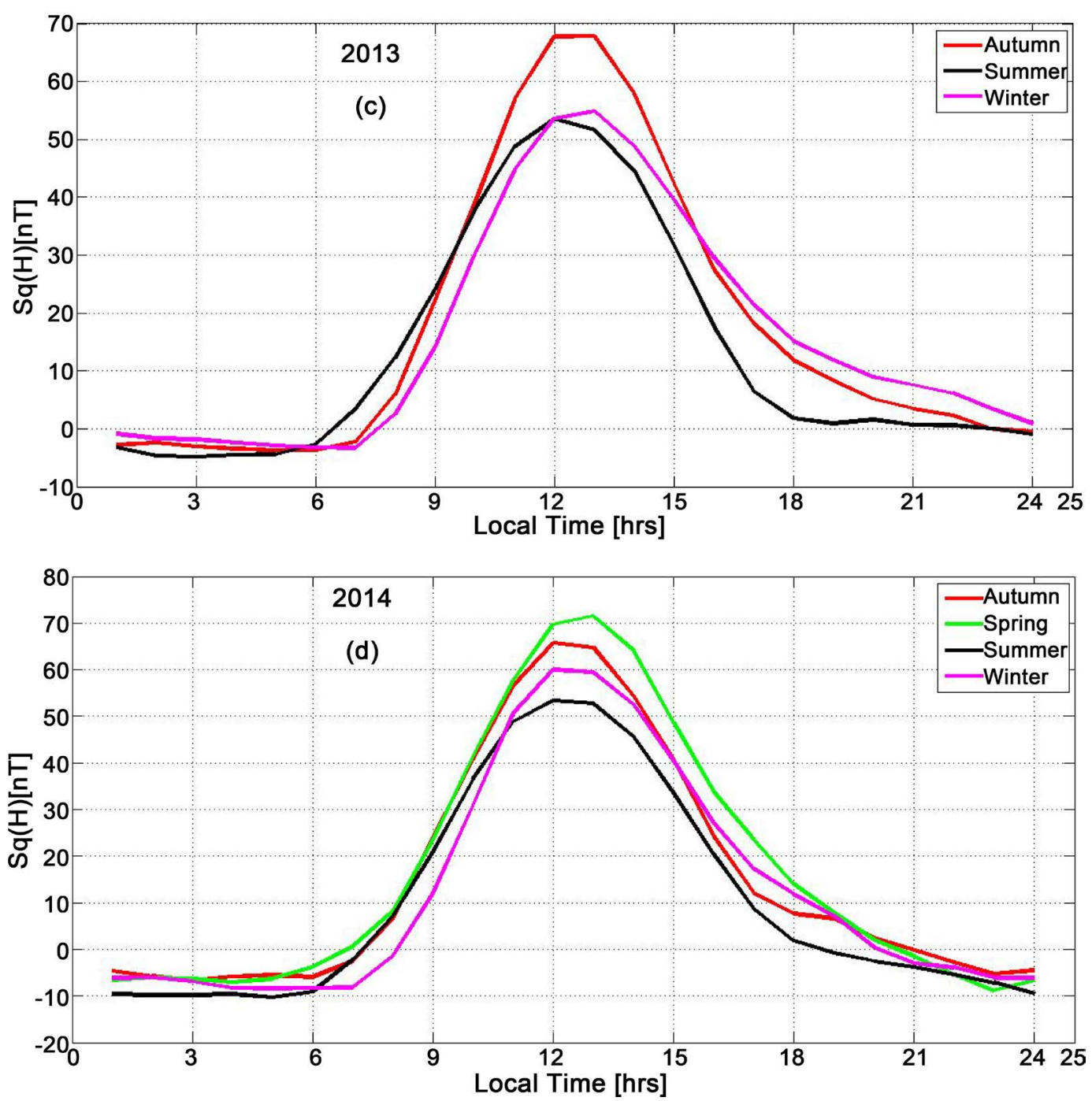

Figure 7. Seasonal variations of Sq (H) from 2011 to 2014. Each figure shows 4 curves corresponding to the variation of either Sq $(\mathrm{H})$ over the 4 seasons (autumn, spring, summer and winter) and represents the seasonal variation across each individual year.

thunderclouds. He reveals in his works the existence of electrons in the troposphere whose circulation in this layer of the atmosphere give birth to the equatorial tropospheric electro-ejector in a low layer denoted (LL-EEJ), could affect to ground-based instruments. Therefore the observations made at our station would be an ideal example.

The Sq variation of the horizontal component of the earth's magnetic field observed at the Yaoundé station shows a unique variation pattern for the different months and seasons (see Figure 3 and Figure 6). This shape do not correspond only to the ideal Sq current system (Figure 2) but also to others equivalent system currents represented by three models called $\mathrm{R}$, $\mathrm{T}$ and $\mathrm{F}$ [22] presented in Figure 8. The left panel of this figure shows models $\mathrm{R}, \mathrm{T}$ and $\mathrm{F}$ and the right panel shows the current SqX systems that are caused by each model. The morphology of the diurnal, monthly and seasonal variations of the $\mathrm{H}$ horizontal component observed at the Yaoundé station correspond to the effect of the $\mathrm{R}$ model where the Sq values are mainly positive. 


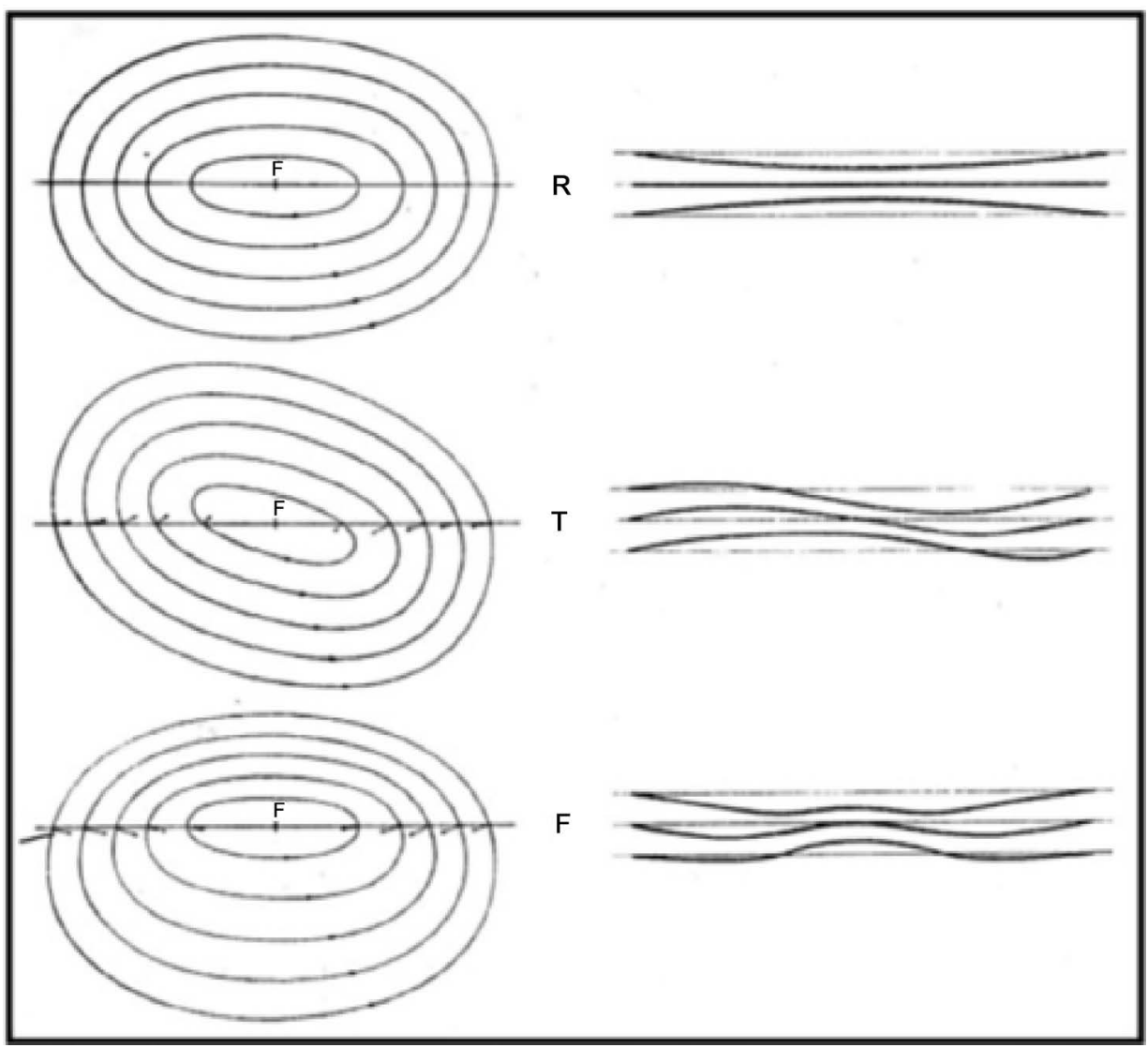

Figure 8. Model of equivalent current systems from Mayaud, 1965. The left panel shows the pattern of the $\mathrm{R}, \mathrm{T}$ and $\mathrm{F}$ models and the right panel shows the diurnal variation of the Sq X component for each model.

The R model current ("ideal Sq system") is a current system with oval or elliptical lines. The short axis is north-south. Its focus is located at mid-latitudes. The $\mathrm{R}$ model has an inclination of the small north-south axis which is no longer directed north-south as it is for model $\mathrm{T}$. the model $\mathrm{R}$ does not cause any variation in the SqX component at the latitude of the focus. However, at the either side of the focus, it causes a minimum pure (P-type form) above the focus and a pure maximum (E-type form) below the focus [10]. At the Yaoundé station, the effect of the $\mathrm{R}$ model is observed from January to December on diurnal, monthly and seasonal variations. Indeed, from January to December, the $\mathrm{SqH}$ presents a pure maximum i-e with predominantly positive values.

\section{Conclusions}

The aim of this work was to analyze the diurnal, monthly and seasonal variations of the Sq (H) observed in Yaoundé using the data provided by AMBER station of Yaoundé during quiet magnetic days. The results obtained highlight the following characteristics of Sq:

- The large amplitude variation values of $\mathrm{Sq}(\mathrm{H})$ are those of the two equinoxes while the smallest are observed in the winter and summer seasons.

- The amplitude of the Sq $(\mathrm{H})$ of the spring equinox is different from that of 
the autumn equinox: there is an equinoctial asymmetry at Yaoundé.

- The Sq $(\mathrm{H})$ values are negative in night time for all four seasons. It is a typical signature of our station. These negative Sq $(\mathrm{H})$ value in our station could be due to other physical processes, another type of current (external current during night time which could be west or east currents) or the existence of a strong induced current at Yaoundé.

- Although the data used in this study are insufficient, it is noted a strong correlation between the amplitude of the $\mathrm{Sq}(\mathrm{H})$ and the solar cycle variations: it is large during the maximum phases of the solar cycle and low during the minimum of the solar cycle.

- The patterns of $\mathrm{Sq}(\mathrm{H})$ variations correspond to the $\mathrm{R}$ model, from January to December, the $\mathrm{Sq}(\mathrm{H})$ shows a form of E-type (i-th maximum pure).

In the next work, we will make a comparative study of the mean diurnal variation of Sq with other stations in other longitude areas in order to highlight the characteristics of the Sq in Yaoundé, to study its longitudinal variability and also to understand the dynamics of the ionospheric electric current system of the Southern Hemisphere. The study period could also be extended over a large number of years of data to determine the effect of solar activity on the Sq variation at our station.

\section{Acknowledgements}

The authors thank Yizengaw E., Zesta E., Moldwin M. B. and the rest of the AMBER and SAMBA team for the data. AMBER is operated by Boston College and funded by NASA and AFOSR. SAMBA is also operated by UCLA and funded by NSF.

\section{References}

[1] Stewart, B. (1882) Terrestrial Magnetism. In: Baynes, T.S. and Smith, W.R., Eds., Encyclopedia Britannica, 9th Edition, Vol. 16, A \& C Black, Edinburgh, 159-184.

[2] Chapman, S. and Bartels, J. (1940) Geomagnetism. Oxford University Press, Oxford, $1049 \mathrm{p}$.

[3] Johnston, H.F. (1943) Mean, K-Indices from Twenty One Magnetic Observatories and Five Quiet Days and Five Disturbed Days for 1942. Terrestrial Magnetism and Atmospheric Electricity, 47, 219. https://doi.org/10.1029/TE048i004p00219

[4] Christine, A. (2014) On the Scientific Contributions of Pierre-Noël Mayaud. IAGA Assembly, July 2005, Toulouse.

[5] Yizengaw, E. and Moldwin, M.B. (2009) African Meridian B-Field Education and Research (AMBER) Array. Earth Moon Planet, 104, 237-246. https://doi.org/10.1007/s11038-008-9287-2

[6] Okeke, F.N. and Hamano, Y. (2000) Daily Variations of Geomagnetic HD and Z-Field at Equatorial Latitudes. Earth Planets Space, 52, 237-243. https://doi.org/10.1186/BF03351632

[7] Chapman, S. (1919) The Solar and Lunar Variation of the Earth's Magnetism. Philosophical Transactions of the Royal Society of London A, 218, 1-118. https://doi.org/10.1098/rsta.1919.0001

[8] Yizengaw, E. et al. (2014) The Longitudinal Variability of Equatorial Electrojet and 
Vertical Drift Velocity in the African and American Sectors. Annals of Geophysics, 32, 231-238.

[9] Pham Thi, T.H., Amory-Mazaudier, C. and Le Huy, M. (2011) Sq Field Characteristics at Phu Thuy, Vietnam, during Solar Cycle 23: Comparisons with Sq Field in Other Longitude Sectors. Annales Geophysicae, 29, 1-17. https://doi.org/10.5194/angeo-29-1-2011

[10] Anad, F., et al. (2016) Sq Solar Variation at Medea Observatory (Algeria), from 2008 to 2011. Advances in Space Research, 58, 1682-1695.

[11] Yizengaw, E., Doherty, P. and Fuller-Rowell, T. (2013a) Is Space Weather Different Over Africa, and If So, Why? AGU Chapman Conference Report. Space Weather, 11, 389-391. https://doi.org/10.1002/swe.20063

[12] Rabiu, A.B., Mamukuyomi, A.I. and Joshua, E.O. (2007) Variability of Equatorial Ionosphere Inferred from Geomagnetic Field Measurements. Bulletin of the Astronomical Society of India, 35, 607-618.

[13] Obiekezie, T.N. and Agbo, G.A. (2008) Day to Day Variability of Sq (H) Variation in the Indian Sector. JANS. 3, 81-85.

[14] Obiekezie, T.N. and Okeke, F.N. (2009) Variations of Geomagnetic HD and Z Field Intensities on Quiet Days at West African latitudes, Moldavian. Journal of Physical Science, 8, 366-372.

[15] Obiekezie, T.N. and Obiadazie, S.C. (2013) The Variability of H Component of Geomagnetic Field at the African Sector. Physical Review \& Research International, 3, 154-160.

[16] Honore, M.E., Comelo, K.D. and Cesar, M.B. (2014) Day-to-Day Variability of H Component of Geomagnetic Field in Central African Sector Provided by Yaoundé-Cameroon Amber Station. International Journal of Geosciences, 5, 11901205. https://doi.org/10.4236/ijg.2014.510099

[17] Campbell, W.H. (1997) Introduction to Geomagnetic Fields. Cambridge University Press, Cambridge.

[18] Vestine, E. (1947) The Geomagnetic Field, Its Description and Analysis. Carnegie Institute, Washington DC, $580 \mathrm{p}$.

[19] Matsushita, S. and Campbell, W.H. (1967) Physics of Geomagnetic Phenomena. Vol. 1, Academic Press, New York, 1, 1398 p.

[20] Lloyd, H. (1861) On Earth-Currents, and Their Connexion with the Diurnal Changes of the Horizontal Magnetic Needle. The Transactions of the Royal Irish Academy, 24, 115-141.

[21] Amory-Mazaudier, C. (1983) Contribution à l'étude des courants électriques de moyennes latitudes en relation avec les observations du champ géomagnétique terrestre. Thèse de Doctorat d'Etat, Université Pierre et Marie Curie, Paris.

[22] Mayaud, P.N. (1965) Analyse morphologique de la variabilite jour à jourde la variation journalière régulière $\mathrm{Sr}$ du champ magnétique terrestre. Le système de courants CM (régions non polaires). Annals of Geophysics, 21, 514-544.

[23] Onwumechili, C.A. (1960) Fluctuations in the Geomagnetic Field near the Magnetic Equator. Journal of Atmospheric and Terrestrial Physics, 17, 286-294. https://doi.org/10.1016/0021-9169(60)90141-0

[24] Matsushita, S. (1969) Dynamo Currents, Winds, and Electric Fields. Radio Science, 4, 771. https://doi.org/10.1029/RS004i009p00771

[25] Abbas, M., et al. (2012) Variability of Electrojet Strength along the Magnetic Equator using MAGDAS/CPMN Data. Journal of Information and Data Management, 1 , 
10-13.

[26] Onwumechili, C.A. (1967) In: Matsushita, S. and Campbell, W.H., Eds., Physics of Geomagnetic Phenomena, Vol. 1, Academic Press, New York, 425-507.

https://doi.org/10.1016/B978-0-12-480301-5.50014-8

[27] Onwumechili, C.A. (1997) The Equatorial Electrojet. Gordon and Breach Science Publishers, Amsterdam, 627.

[28] Forbes, J.M. (1981) The Equatorial Electrojet. Reviews of Geophysics and Space Physics, 19, 469-504. https://doi.org/10.1029/RG019i003p00469

[29] Mbane, B.C. (2015) Useful and Unique Descriptions of Tropospheric Processes Which Produce Oxygen and Thereafter Give Birth to Equatorial Electro-Jets. International Journal of Geosciences, 6, 1248-1253.

https://doi.org/10.4236/ijg.2015.611098

Submit or recommend next manuscript to SCIRP and we will provide best service for you:

Accepting pre-submission inquiries through Email, Facebook, LinkedIn, Twitter, etc. A wide selection of journals (inclusive of 9 subjects, more than 200 journals)

Providing 24-hour high-quality service

User-friendly online submission system

Fair and swift peer-review system

Efficient typesetting and proofreading procedure

Display of the result of downloads and visits, as well as the number of cited articles

Maximum dissemination of your research work

Submit your manuscript at: http://papersubmission.scirp.org/

Or contact ijg@scirp.org 